INRA Prod. Anim., 2005, 18 (5), 309-322

\title{
La microflore digestive des volailles : facteurs de variation et conséquences pour l'animal
}

\author{
I. GABRIEL ${ }^{1}$, S. MALLET ${ }^{1}$, P. SIBILLE ${ }^{2}$ \\ ${ }^{1}$ INRA, Station de Recherches Avicoles, F-37380 Nouzilly \\ 2 INRA, Bio Agresseur Santé Environnement, F-37380 Nouzilly \\ Courriel : email : gabriel@tours.inra.fr
} \begin{abstract}
des stratégies efficaces de substitution aux antibiotiques.
Pour connaître l'effet de la microflore chez l'oiseau, la plupart des travaux ont été effectués chez le poulet, en comparant des animaux conventionnels à des animaux axéniques. Ces travaux ont été réalisés dans les années 19701980 par des équipes anglaises (Barnes E.M., Coates M.E., Fuller R.) et plus récemment (1980-1990) par des équipes japonaises (Furuse M., Okumu-

qui peuvent entraîner des modifications, ainsi que les métabolites produits par la microflore. Dans une deuxième étape, nous nous intéresserons aux effets de la flore sur la physiologie digestive, la valeur nutritionnelle de l'aliment, la santé de l'animal, et les conséquences de la présence ou des changements dans la microflore sur les performances et la qualité des produits animaux.
\end{abstract}

La flore du tube digestif des oiseaux a été considérée jusqu’à présent comme jouant un rôle mineur comparativement à celle du côlon des mammifères. Avec la suppression annoncée des antibiotiques facteurs de croissance pour 2006 en Europe, son importance va s'accroître. Une meilleure connaissance de cette microflore et de ses effets s'avère nécessaire pour proposer ra J.). Par ailleurs, d'autres études ont été effectuées en comparant des animaux nourris avec des aliments contenant ou non des antibiotiques (ou des probiotiques). Elles montrent l'influence d'une modification de la flore, mais pas les effets de la présence ou de l'absence de la flore digestive. Avec l'annonce de la suppression des Antibiotiques Facteurs de Croissance (AFC) on assiste à un nouveau développement des études de la microflore des animaux d'élevage dont les volailles, ainsi que des modifications qu'elle peut subir.

La flore digestive des oiseaux a été très étudiée, et s'avère différente de celle des mammifères (Smith 1965) probablement du fait de différences anatomiques et physiologiques. En particulier, les mammifères ont un côlon très développé par rapport aux oiseaux.

Nous proposons dans cette synthèse de présenter l'état actuel des connaissances sur la microflore digestive des volailles. Dans une première étape, nous présenterons le type de flore généralement observé dans le tube digestif de ces animaux, les différents facteurs

\section{1 / Caractérisation de la flo- re digestive du poulet}

Les nombreuses études effectuées sur la flore digestive des oiseaux depuis les années 1950 ont fait appel aux cultures de bactéries sur milieu sélectif. Or une proportion très élevée de bactéries, jusqu'à $90 \%$ selon les estimations, n'est pas cultivable (Lan et al 2002). Les méthodes classiques de microbiologie n'apportent donc qu'une image très partielle de la réalité de l'écosystème digestif. Pour résoudre ce problème, des techniques de biologie moléculaire ont été développées. Elles permettent de mettre en évidence, grâce à leur ADN ribosomal $16 \mathrm{~S}$, les microorganismes quelles que soient leurs conditions de viabilité. Bien qu'elles aient, elles aussi, certaines limites techniques liées entre autres aux conditions d'extraction de l'ADN ou des biais au cours de l'étape d'amplification de l'ADN, elles apportent une image beaucoup plus précise et plus complète de la diversité microbienne que les cultures. Dans le cas des oiseaux, ces techniques n'en étant qu'à leur début, les informations disponibles sont actuellement très incomplètes. La flore digestive des oiseaux et ses variations restent donc mal connues, et par conséquent à explorer.

\section{1 / Description et localisation dans le tractus digestif}

La flore digestive au sens large comprend les organismes unicellulaires situés dans le tractus digestif, c'est-àdire les bactéries, les champignons et les protozoaires. En ce qui concerne les populations bactériennes, qui sont les micro-organismes prédominants, elles représentent une large gamme de types métaboliques et morphologiques. Leur nombre total est plus important que le nombre de cellules eucaryotes constituant le corps de l'hôte. On distingue les bactéries dominantes $\left(>10^{6}\right.$ Unités Formant Colonies (UFC) /g contenu), sous-dominantes $\left(10^{5}\right.$ à $10^{3}$ UFC / g contenu), et résiduelles $\left(<10^{3} \mathrm{UFC} / \mathrm{g}\right.$ contenu). Chez le poulet, les sites principaux d'activité bactérienne sont le jabot, les caeca et, dans une moindre mesure, l'intestin grêle (Fuller 1984). Ainsi, dans les caeca et l'iléon, on trouve $10^{11}$ et $10^{9}$ bactéries par g de contenu respectivement (Apajalahti et al 2004). Compte tenu des nombreux facteurs modifiant la flore, les différences méthodologiques entre les études (type de régime dont la présence ou non d'antibiotique, souche d'animaux, etc.), empêchent toute généralisation de description de la flore. Par ailleurs, les études effectuées sur la microflore des oiseaux ont concerné principalement les caeca. 
Tableau 1. Composition de la flore le long du tractus digestif du poulet déterminée par dénombrements bactériens (Smith 1965) (1).

\begin{tabular}{|l|c|c|c|c|c|c|c|}
\hline \multirow{2}{*}{$\begin{array}{l}\text { Groupes } \\
\text { majoritaires }\end{array}$} & \multicolumn{6}{|c|}{ Nombre de bactéries viables (log 10 UFC / g de contenu) } \\
\cline { 2 - 8 } & Jabot & Gésier & $\begin{array}{c}\text { Intestin } \\
\mathbf{1}(\mathbf{2})\end{array}$ & $\begin{array}{c}\text { Intestin } \\
\mathbf{3}\end{array}$ & $\begin{array}{c}\text { Intestin } \\
\mathbf{5}\end{array}$ & $\begin{array}{c}\text { Intestin } \\
\mathbf{7}\end{array}$ & Caeca \\
\hline Lactobacilles & 8,7 & 7,3 & 8,0 & 8,2 & 8,2 & 8,6 & 8,7 \\
Streptocoques & 4,0 & 3,7 & 4,0 & 4,0 & 3,7 & 4,2 & 6,7 \\
Escherichia coli & 1,7 & nd & 2,0 & 1,7 & 1,7 & 2,7 & 5,6 \\
Levures & 2,7 & nd & 1,7 & nd & 1,7 & nd & 2,0 \\
Clostridium welchi & nd & nd & nd & nd & nd & nd & 1,7 \\
Bacteroïdes & nd & nd & nd & nd & nd & nd & 8,7 \\
\hline
\end{tabular}

UFC : Unité Formant Colonie.

nd : organisme non détecté, c'est-à-dire quantité dont le $\log _{10}$ est inférieur à $1,7 / \mathrm{g}$.

(1) Poulets de chair adultes issus d'un élevage (6 individus), consommant un régime composé de céréales et de farine de poisson (10-15\%), sans antibiotique.

(2) L'intestin a été divisé en 7 parties : différentes portions ont été étudiées (la $1^{\mathrm{re}}$, la $3^{\mathrm{e}}$, la $5^{\mathrm{e}}$ et la $7^{\mathrm{e}}$ partie).

a) Données de microbiologie classique (culture)

Ces méthodes montrent que la flore, constituée principalement de bactéries à Gram positif, est composée essentiellement d'anaérobies facultatives du jabot à l'iléon terminal, alors que les caeca contiennent en plus des anaérobies strictes, ces dernières étant dominantes (Fuller 1984, tableau 1). Dans le jabot, on trouve principalement des lactobacilles qui sont attachés à l'épithélium et forment presque une couche continue. On trouve aussi des streptocoques, des coliformes et des levures. Dans le gésier et le proventricule, le faible $\mathrm{pH}$ (figure 1) fait chuter la population bactérienne. Dans le duodénum, les conditions ne sont pas propices au développement de la flore : présence de nombreuses enzymes, forte pression en oxygène, présence de fortes concentrations de composés antimicrobiens tels que les sels biliaires et mouvements de reflux du jéjunum au gésier entraînant une modification rapide des conditions de milieu. Plus loin dans l'intestin, l'environnement devient plus favorable à la croissance bactérienne en raison de la plus faible pression d'oxygène et de la faible concentration en enzymes et en sels biliaires (réabsorbés par l'hôte et dégradés en partie par la microflore). Cependant, si les aliments sont bien digérés, la flore est limitée par manque de substrat. Globalement dans l'intestin grêle, on trouve principalement des bactéries anaérobies facultatives (lactobacilles, streptocoques et coliformes). Dans les caeca, les anaérobies strictes comme les Eubacterium, des bifidobactéries ou des clostridies, deviennent majoritaires, mais les bactéries anaérobies facultatives sont aussi présentes. La faible fréquence du renouvellement du contenu de cet organe ( 1 à 2 fois par jour) favorise le développement des bactéries. Les méthodes de cultures conventionnelles ont conduit à l'identification chez le poulet de 29 genres bactériens, chaque genre étant représenté par 3 à 4 espèces, et chaque espèce par 3 à 4 types métaboliques différents, ce qui ferait plus de 200 souches différentes (Fuller 1984, Mead 1989). D'autres organismes dont l'activité métabolique a été mise en évidence n'ont pas pu être isolés et caractérisés du fait de leur besoin d'anaérobiose stricte ou de l'ignorance des composants nécessaires à leur croissance (Mead 1989). Ainsi, seulement $25 \%$ des souches seraient identifiées.

Figure 1. Schéma du tractus digestif des volailles et valeurs des pH des contenus digestifs (Farner 1942).

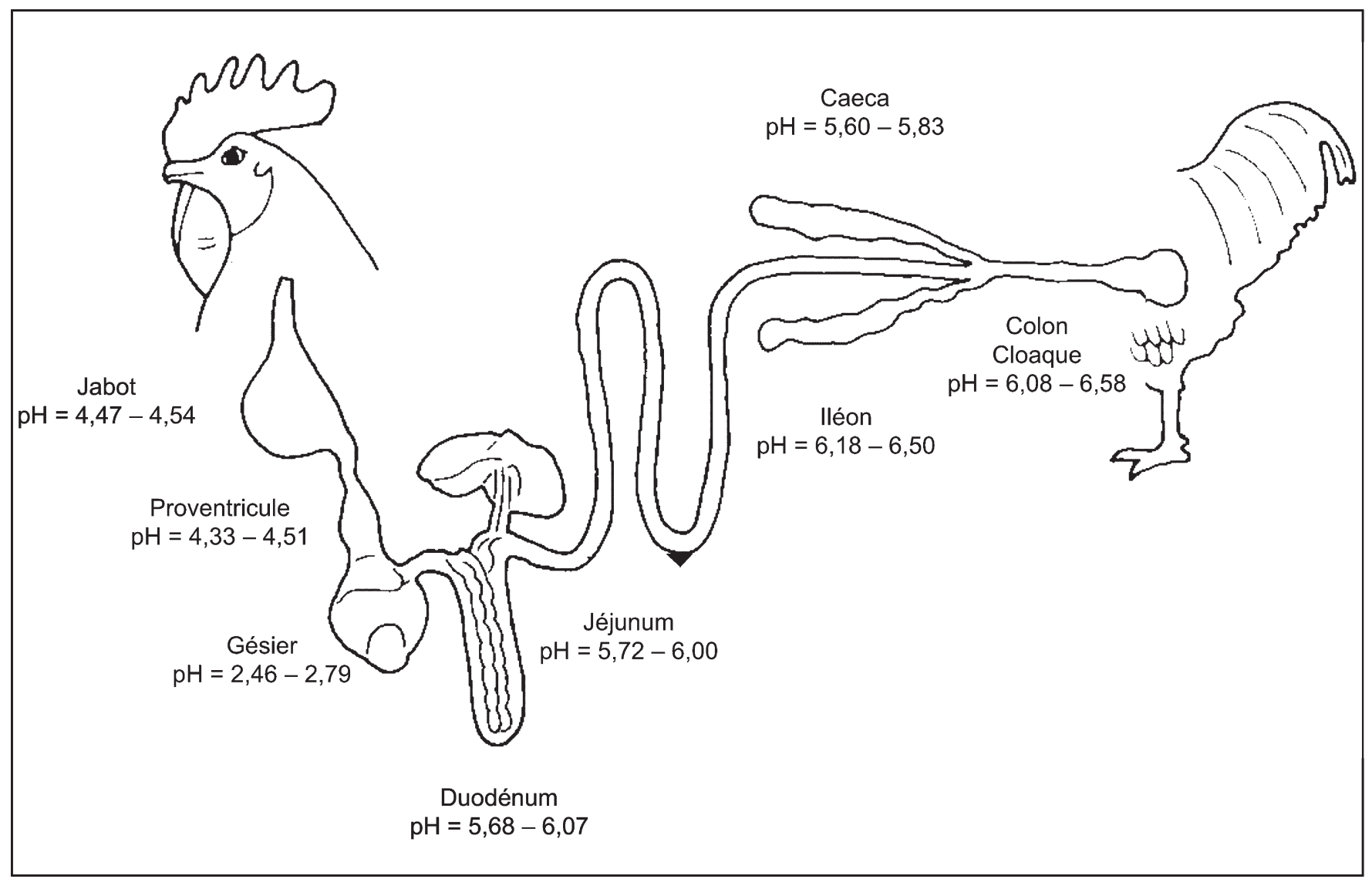


Bien que la grande majorité des études concerne le poulet, quelques rares travaux ont été effectués sur d'autres espèces avicoles d'intérêt économique (Smith 1965, Barnes 1979, Mead 1989). Ainsi, par rapport au poulet, le canard présente une flore du jabot jusqu'à l'intestin grêle plus pauvre en lactobacilles, plus riche en coliformes, clostridies et streptocoques, et une flore caecale plus abondante. Chez la dinde, la flore caecale présente des similitudes avec celle des poulets.

\section{b) Données de microbiologie molécu- laire}

Les nouvelles données issues d'approches moléculaires confirment certains résultats obtenus par les méthodes de culture conventionnelle. Ainsi, la présence majoritaire des bactéries à Gram positif dans le tube digestif et des lactobacilles au niveau de l'intestin grêle, ainsi que la diversité plus importante des populations bactériennes au niveau des caeca sont confirmées (Gong et al 2002, Lu et al 2003, tableau 2).

Les méthodes moléculaires font aussi apparaître des différences. Ainsi les Clostridiaceae seraient beaucoup plus importantes quantitativement surtout dans les caeca ( $\mathrm{Lu}$ et al 2003, tableau 2). Cependant les biais inhérents aux approches moléculaires peuvent aussi conduire à sous-estimer ou à surestimer certaines espèces. Ces approches permettent de mettre en évi- dence plus de bactéries en raison de l'absence de la sélection des microorganismes en fonction de la possibilité ou non de les cultiver. Elles permettent par ailleurs de définir les bactéries jusqu'à leur espèce. Par exemple, en étudiant 1656 séquences partielles de gène d'ARNr $16 \mathrm{~S}$ bactérien issus des caeca, Zhu et al (2002) ont identifié 243 séquences différentes représentant 50 groupes ou sous-groupes phylogénétiques de bactéries, avec $89 \%$ des séquences appartenant à 4 groupes phylogénétiques. De leur coté, Apajalahti et al (2004) ont trouvé 640 espèces différentes et 140 genres bactériens différents. De nombreuses espèces mises en évidence chez le poulet sont également présentes chez l'homme. D'autres espèces non connues pourraient représenter des proportions très importantes, jusqu'à $90 \%$ des espèces selon les auteurs (Gong et al 2002, Lan et al 2002, Zhu et al 2002, Apajalahti et al 2004).

\section{c) Flore luminale et flore $d u$ mucus ou des muqueuses}

La flore digestive peut se trouver dans la lumière intestinale, enfouie dans la couche de mucus ou adhérante à la muqueuse digestive où elle peut former des couches de cellules très importantes (Fuller 1984). La flore luminale dépend des nutriments disponibles, de la vitesse de transit et de la présence ou non de substances antimicrobiennes. La flore mucosale

Tableau 2. Composition de la flore digestive intestinale et caecale du poulet déterminée par clonage et séquençage (Lu et al 2003) (1).

\begin{tabular}{|c|c|c|c|}
\hline \multirow{2}{*}{ Groupe } & \multirow{2}{*}{ Classe } & \multicolumn{2}{|c|}{$\%$ de classe $(2,3)$} \\
\hline & & Jéjunum + Iléon & Caeca \\
\hline $\begin{array}{l}\text { Gram +, faible G+C } \\
\text { Iléon : } 94,2 \% \text {; Caeca : } 76,9 \%\end{array}$ & $\begin{array}{l}\text { Lactobacillaceae } \\
\text { Clostridiaceae (6) } \\
\text { Bacillaceae } \\
\text { Staphylococcaceae } \\
\text { Streptococcaceae } \\
\text { Enterococcaceae }\end{array}$ & $\begin{array}{c}68,7 \\
10,8 \\
0,7 \\
1,0 \\
6,6 \\
6,4\end{array}$ & $\begin{array}{c}8,2 \\
65,6 \\
1,4 \\
0 \\
0,7 \\
1,0\end{array}$ \\
\hline $\begin{array}{l}\text { Gram +, fort G+C } \\
\text { lléon : } 0,9 \% ; \text { Caeca : } 13,9 \%\end{array}$ & $\begin{array}{l}\text { Fusobacteriaceae } \\
\text { Bifidobacteriaceae }\end{array}$ & $\begin{array}{l}0,7 \\
0,2\end{array}$ & $\begin{array}{c}13,9 \\
0\end{array}$ \\
\hline $\begin{array}{l}\text { Gram - , protéobactéries (4) } \\
\text { lléon : } 2,3 \% \text {; Caeca : } 2,8 \%\end{array}$ & & 2,3 & 2,8 \\
\hline $\begin{array}{l}\text { Gram - (5) } \\
\text { Iléon : 0,6\% ; Caeca : } 5,2 \%\end{array}$ & $\begin{array}{l}\text { Flavobacteriaceae } \\
\text { Bacteroïdaceae }\end{array}$ & $\begin{array}{c}0 \\
0,6\end{array}$ & $\begin{array}{l}0,2 \\
5,0\end{array}$ \\
\hline
\end{tabular}

(1) Poulets de chair à croissance rapide élevés en conditions commerciales, consommant un régime composé de maïs et de soja, sans antibiotique.

(2) Valeur moyenne pour des animaux de 3 à 49 j (10 individus de 3 et 7 j, 5 individus de 14 à 49 j).

(3) 614 et 616 séquences pour l'intestin et les caeca respectivement, avec séquençage partiel (350 à $410 \mathrm{pb})$.

(4) Ochrobacterium, Alcaligenes, Escherichia, Campylobacter.

(5) Cytophaga, Flexibacter, Bacteroïdes.

(6) Clostridium, Ruminococcus, Eubacterium. dépend de l'expression par l'hôte de sites d'adhésion spécifiques sur les membranes des entérocytes, de la vitesse de production du mucus, de la production d'anticorps (Ig) sécrétoires, et de l'extrusion de matériel cellulaire de la membrane. En pratique, un organisme ne peut coloniser l'intestin que s'il se multiplie à une vitesse suffisamment rapide pour compenser son élimination par le transit digestif, ou s'il s'attache à la muqueuse. Les bactéries ainsi fixées sont particulièrement importantes du fait de leur contact étroit avec l'hôte et de leur rôle dans le contrôle des pathogènes, de la modulation de l'immunité et de leurs effets sur l'absorption des nutriments par l'hôte. Cette flore a cependant été peu étudiée, bien qu'elle soit différente de la flore luminale (Gong et al 2002, Zhu et al 2002).

\section{2 / Facteurs de variation}

La flore digestive présente des variations entre les individus et dépend de leur âge, mais elle peut aussi être modifiée par de nombreux facteurs extérieurs.

\section{a) Souche, sexe, individu}

La flore digestive semble différer selon la souche et le sexe des animaux. Chaque individu présente une communauté bactérienne digestive qui lui est propre (Zhu et al 2002). Ceci suggère que des facteurs spécifiques de l'hôte interviennent dans l'établissement de la flore intestinale. Chez l'homme, la microflore digestive dépendrait de facteurs génétiques de l'individu (Zoetendal et al 2001). Les caractéristiques immunologiques de l'hôte, des récepteurs spécifiques pour les bactéries ainsi que des systèmes de communication avec les bactéries pourraient être des facteurs importants dans l'établissement d'une communauté bactérienne spécifique de l'hôte. Cette hypothèse du rôle de la génétique dans l'établissement de la flore digestive nécessite de plus amples investigations.

\section{b) Cinétique d'implantation}

A l'éclosion, le tube digestif est stérile. L'implantation de la flore dépend de l'environnement de l'œuf au moment de l'éclosion qui définit l'ordre dans lequel les animaux sont exposés aux micro-organismes, de leur aptitude à coloniser l'intestin (besoin en nutriments, lieu de développement) et des interactions entre microorganismes. 
Figure 2. Evolution de la composition de la flore digestive iléale du poulet en fonction de l'âge déterminée par dénombrements bactériens (Knarreborg et al 2002) (1,2).

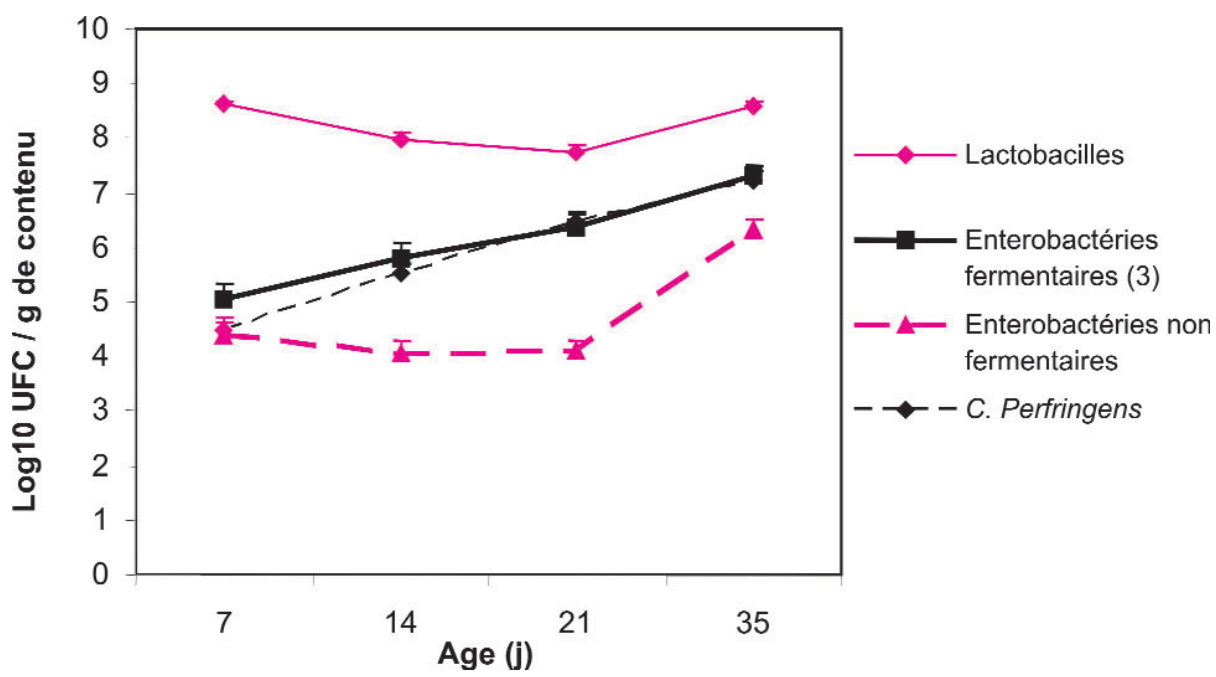

UFC : Unité Formant Colonie.

(1) Poulets de chair (mâle) à croissance rapide élevés au sol en conditions expérimentales (parquet), consommant un régime composé de blé, soja, pois, farine de poisson et graisse végétale, sans antibiotique.

(2) Nombre d'individus: 16, 10, 8 et 6 à 7, 14, 21 et 35 j respectivement.

(3) Fermentation du lactose.

La flore augmente rapidement après l'éclosion. Ainsi dès le premier jour, l'iléon et les caeca hébergent $10^{8}$ et

$10^{10}$ bactéries par $\mathrm{g}$ de contenu digestif (Apajalahti et al 2004). Leur nombre atteint $10^{9}$ et $10^{11}$ bactéries par g à
3 jours et reste relativement stable jusqu'à l'âge de 30 jours. D'un point de vue qualitatif, dès le premier jour, les coliformes, les streptocoques et les clostridies colonisent rapidement le tube digestif, du jabot aux caeca, alors que les lactobacilles ne sont pas mis en évidence avant 3 jours et les bactéroïdes pas avant 5 jours et seulement au niveau des caeca (Fuller 1984). La flore, aussi bien intestinale que caecale, se diversifie avec l'âge (Knarreborg et al 2002, Lu et al 2003). Ainsi, dans l'iléon, on observe avec l'âge différentes espèces de lactobacilles, une augmentation transitoire des streptocoques, et une augmentation continue de Clostridium perfringens (Knarreborg et al 2002, Lu et al 2003, figure 2, tableau 3). Dans les caeca, bien que les clostridies soient toujours majoritaires, les lactobacilles sont initialement présents en proportions importantes à 3 jours d'âge, puis diminuent au profit des clostridies à 7 jours, puis des fusobactéries à 21 jours, et à nouveau des clostridies à l'âge de 49 jours (Lu et al 2003, tableau 3).

Tableau 3. Evolution de la composition de la flore digestive intestinale du poulet en fonction de l'âge déterminée par clonage et séquençage (Lu et al 2003) (1).

\begin{tabular}{|c|c|c|c|c|c|c|c|c|}
\hline \multirow{2}{*}{$\begin{array}{l}\text { Segment } \\
\text { digestif }\end{array}$} & \multirow{2}{*}{ Groupe } & \multirow{2}{*}{ Classe } & \multicolumn{6}{|c|}{$\%$ de classe $(2,3)$} \\
\hline & & & 3 & 7 & 14 & 21 & 28 & 49 \\
\hline \multirow{10}{*}{$\begin{array}{c}\text { Intestin } \\
\text { (Jéjunum, } \\
\text { iléon) }\end{array}$} & Gram +, faible G + C & Lactobacillaceae & 61,1 & 63,3 & 63,7 & 65,8 & 86,3 & 69,8 \\
\hline & & Clostridiaceae (7) & 16,9 & 1,1 & 6,9 & 14,9 & 6,4 & 19,2 \\
\hline & & Bacillaceae & & & & & & 4,0 \\
\hline & & Staphylococcaceae & 2,1 & & & 2,6 & & \\
\hline & & Streptococcaceae & 2,1 & 17,8 & 16,7 & 2,6 & 0,9 & \\
\hline & & Enterococcaceae & 3,2 & 15,6 & 12,8 & 2,6 & 2,7 & 2,0 \\
\hline & Gram + , fort $G+C$ & $\begin{array}{l}\text { Fusobacteriaceae } \\
\text { Bifidobacteriaceae }\end{array}$ & & 1,1 & & 4,4 & & \\
\hline & Gram - , protéobactéries (4) & & 13,7 & & & & & \\
\hline & Gram - (5) & Bacteroïdaceae & & & & 2,6 & & 1,0 \\
\hline & Bactéries inconnues & & 2,1 & & & 4,4 & 3,6 & 4,0 \\
\hline \multirow[t]{10}{*}{ Caeca } & Gram +, faible G + C & Lactobacillaceae & 25,7 & 4,3 & 9,9 & 1,0 & 0,9 & 7,2 \\
\hline & & Clostridiaceae (7) & 51,4 & 85 & 73 & 56,6 & 56,1 & 74,2 \\
\hline & & Bacillaceae & & & 2,7 & 4,0 & 1,8 & \\
\hline & & Streptococcaceae & 2,9 & & & & & 1,0 \\
\hline & & Enterococcaceae & 1,9 & 2,2 & 0,9 & & & 2,0 \\
\hline & Gram + , fort G + C & Fusobacteriaceae & & 2,2 & 9,0 & 27,3 & 35,1 & 7,2 \\
\hline & Gram -, protéobactéries (6) & & 15,2 & 2,2 & 9,9 & 27,3 & 35,1 & 7,2 \\
\hline & Gram - (4) & Flavobacteriaceae & 1,0 & & & & & \\
\hline & & Bacteroïdaceae & 1,0 & 5,4 & 3,6 & 10,1 & 5,3 & 5,2 \\
\hline & Bactéries inconnues & & 1,0 & 1,1 & & 1,0 & 0,9 & 3,1 \\
\hline
\end{tabular}

(1) Poulets de chair à croissance rapide élevés en conditions commerciales, consommant un régime composé de maïs et de soja, sans antibiotique.

(2) 10 individus de 3 et $7 \mathrm{j}, 5$ individus de 14 à $49 \mathrm{j}$.

(3) Entre 90 et 114 clones analysés par âge.

(4) Ochrobacterium, Alcaligenes, A. faecalis, Campylobacter, Escherichia.

(5) Cytophaga, Flexibacter, Bacteroïdes.

(6) Ochrobacterium anthropi, Achromobacter xylosoxidans, Escherichia coli.

(7) Clostridium, Ruminococcus, Eubacterium. 


\section{c) Environnement}

Selon le milieu d'élevage, la microflore est différente. Des populations plus fortes sont observées chez des animaux élevés au sol (sur litière propre ou contaminée) par rapport à des animaux élevés en cages individuelles (Mallet et al 2001). L'augmentation de la densité d'élevage ou les stress thermiques semblent globalement augmenter les bactéries néfastes au détriment des bactéries bénéfiques (Suzuki et al 1989). La présence de parasites intestinaux comme les coccidies, entraînant la dégradation de la muqueuse intestinale donc la production de nouveaux substrats pour la microflore, conduit à une modification de celle-ci (Kimura et al 1976). Cependant la flore serait peu modifiée chez les animaux issus d'élevages conduits de façon similaire (Apajalahti et al 2001).

d) Composition et structure des aliments

Hormis l'effet modulateur des antibiotiques dans l'aliment (Knarreborg et al 2002), la flore digestive dépend directement de l'alimentation puisque cette dernière est à l'origine du type de substrat disponible pour la croissance des micro-organismes.

La flore digestive peut être modifiée par le type de céréales, en particulier la présence de polysaccharides non amylacés hydrosolubles, ou par leur mode de présentation. Ainsi, Mathlouti et al (2002) observent une augmentation des populations bactériennes anaérobies facultatives, dont les lactobacilles et les coliformes, avec un régime à base de blé et d'orge au lieu de maïs. La consommation d'un régime contenant du blé sous forme de graines entières par rapport à du blé broyé entraîne une modification de la flore (Apajalahti et al 2001, Gabriel et al 2003, Engberg et al 2004). La granulation de l'aliment, entraine d'après Engberg et al (2002) une augmentation des coliformes et des entérocoques dans l'iléon, ainsi qu'une baisse de Clostridium perfringens et des lactobacilles en fin de tube digestif (caeca et rectum). De même, l'origine des matières grasses (Knarreborg et al 2002), de l'amidon (Weurding 2002) ou des protéines (Jansman et al 2003) peut modifier la flore. Les minéraux et vitamines peuvent avoir un effet sur la flore. Ainsi, Orban et al (1997) ont observé une augmentation des bifidobactéries avec un apport doublé en oligo minéraux et vitamines ( $1 \%$ au lieu de $0,5 \%$ ). De même, Xia et al (2004) ont montré une réduction des populations de clostridies et de coliformes dans l'intestin et les caeca de poulets recevant un supplément de cuivre associé à de la montmorillonite, la supplémentation de cuivre seul étant sans effet.

Ces facteurs sont responsables des différences de flore observées entre des élevages dont les conditions de gestion varient. Ainsi, la flore digestive diffère entre des animaux à croissance rapide élevés en confinement et des animaux élevés en conditions plus extensives, c'est-à-dire avec des souches à croissance lente, une alimentation sans antibiotique, une densité d'élevage plus faible et l'accès à des parcours extérieurs. Des élevages dont les animaux sont issus du même couvoir et consomment le même aliment peuvent aussi présenter des différences de flore $\mathrm{du}$ fait d'une gestion différente des élevages.

\section{2 / Production de métaboli- tes par la flore digestive}

Par fermentation des aliments, de nombreux composés sont produits par la flore digestive (Coates 1980, Furuse et Okumura 1994, figure 3). Ils peuvent être bénéfiques ou néfastes à l'hôte.

\begin{tabular}{|c|c|}
\hline $\begin{array}{l}\text { - Vitamines (1) } \\
\text { - Acide lactique } \\
\text { - Bactériocine } \\
\text { - Métabolites de l'oxygène } \\
\text { - Péroxyde d'hydrogène } \\
\text { - Radicaux libres }\end{array}$ & $\begin{array}{l}\quad \text { Produits néfastes } \\
\\
\text { - Acide cholique } \\
\text { - Enzymes déconjuguant les sels biliaires } \\
\text { - Indole et scatole } \\
\text { - Mercaptan d'éthyl et de méthyl } \\
\text { - Endotoxines } \\
\text { - Entérotoxines } \\
\text { - Substances mutagènes et carcinogènes } \\
\text { - Oligopeptides potentiellement inflammatoires }\end{array}$ \\
\hline $\begin{array}{l}\text { - Acides gras volatils: } \\
\text { - Ammoniac } \\
\text { - Amines (putrescine }\end{array}$ & $\begin{array}{l}\text { pouvant aussi avoir un effet négatif } \\
\text { - Acétate } \\
\text { - Propionate } \\
\text { - Butyrate } \\
\text { - Isobutyrate } \\
\text { - Valérate } \\
\text { - Isovalérate } \\
\\
\text {, spermidine, spermine, histamine) }\end{array}$ \\
\hline
\end{tabular}

(1) Ne seraient pas disponibles pour l'animal, sauf l'acide folique.

\section{1 / Produits bénéfiques}

Les bactéries produisent des vitamines B, K et E (Coates 1980) et différentes substances antimicrobiennes. $\mathrm{Au}$ niveau du jabot, les lactobacilles produisent une grande quantité d'acide lactique, acide gras à chaîne courte non volatil (Fuller 1984). C'est un produit intermédiaire de la fermentation des glucides qui s'accumule par suite de l'inhibition de la production d'Acides Gras Volatils (AGV) à cause du $\mathrm{pH}$ inférieur à 5,5 dans le jabot (figure 1). La production de cet acide est favorable aux lactobacilles mais défavorable aux coliformes et à la plupart des autres bactéries (Fuller 1984). Cet acide gras à chaîne courte est présent en quantité nettement plus faible dans l'intestin grêle et les caeca (tableau 4).

Certaines bactéries, comme les lactobacilles, produisent des substances antimicrobiennes appelées bactériocines qui ont un large spectre d'activité. Ainsi la réutérine secrétée par $L$. reute$r i$ est efficace contre les salmonelles, les coliformes et les campylobacters (Van Immerseel et al 2003a).

Des composés oxygénés (péroxyde d'hydrogène, radicaux libres) sont aussi produits (Piard et Desmazeaud 1991). Le péroxyde d'hydrogène

\section{Figure 3. Métabolites majeurs produits par la microflore.}


Tableau 4. Acides gras à chaîne courte en fin de tube digestif du poulet (Jin et al 1998) (1).

\begin{tabular}{|c|c|c|c|}
\hline \multirow{2}{*}{\multicolumn{2}{|c|}{ Acides gras à chaîne courte }} & \multicolumn{2}{|c|}{$\begin{array}{c}\text { Quantité ( } \mu \mathrm{moL} / \mathrm{mg} \text { de contenu digestif, } \\
\text { moyenne } \pm \text { SE) }\end{array}$} \\
\hline & & Iléon & Caeca \\
\hline Non volatils & $\begin{array}{l}\text { Lactate } \\
\text { Succinate }\end{array}$ & $\begin{aligned} 2,70 & \pm 0,78 \\
0,360 & \pm 0,003\end{aligned}$ & $\begin{array}{l}0,20 \pm 0,07 \\
0,31 \pm 0,05\end{array}$ \\
\hline Volatils & $\begin{array}{l}\text { Acétate } \\
\text { Propionate } \\
\text { Butyrate } \\
\text { Isobutyrate } \\
\text { Isovalérate }\end{array}$ & $\begin{array}{c}8,8 \pm 1,9 \\
-(2) \\
- \\
- \\
9,2 \pm 1,2\end{array}$ & $\begin{array}{c}37,5 \pm 3,7 \\
4,9 \pm 1,4 \\
4,1 \pm 0,8 \\
0,4 \pm 0,2 \\
11,3 \pm 4,1\end{array}$ \\
\hline
\end{tabular}

(1) Poulets de chair (5 animaux de 42 j) à croissance rapide élevés au sol en conditions expérimentales (parquet), consommant un régime composé de maïs, soja et farine de poisson, sans antibiotique.

(2) Quantités très faibles.

conduit à des inhibiteurs ayant des propriétés bactériostatiques pour les lactobacilles et bactéricides pour les bactéries à Gram négatif.

\section{2 / Produits néfastes}

Les bactéries produisent des métabolites qui dans certains cas peuvent être néfastes, voire toxiques. Elles produisent de l'acide cholique qui accélère le renouvellement cellulaire intestinal. Certains acides aminés sont métabolisés en produits toxiques, comme le tryptophane en indole et scatole, ou la cystéine en mercaptan d'éthyl et de méthyl. Les bactéries à Gram négatif produisent des endotoxines libérées lors de la lyse des lipopolysaccharides contenus dans leurs parois cellulaires. Ces endotoxines entraînent de la fièvre et la libération de pyrogènes endogènes agissant sur les centres thermorégulateurs de l'hypothalamus. D'autres toxines peuvent affecter la motricité intestinale entraînant des diarrhées. Certaines bactéries peuvent retoxifier des substances détoxifiées dans le foie, entraîner la formation de substances mutagènes et carcinogènes ou libérer des oligopeptides potentiellement inflammatoires (Broom et al 1993).

\section{3 / Produits à effets mixtes}

La flore bactérienne produit des AGV à chaîne courte et non ramifiée (acétate, propionate, butyrate) ou ramifiée (valérate, isovalérate, isobutyrate). Le type d'AGV et leur quantité dépendent de la nibles. Dans le jabot, l'acide acétique domine, et dans les caeca, en plus de l'acide acétique présent majoritairement, on trouve des quantités non négligeables d'acide butyrique, de petites quantités d'acide propionique ainsi que d'autres acides en moins grande quantité (Fuller 1984, Zhang et al 2003, tableau 5).

Ces AGV ont différents effets bénéfiques. Ils représentent une source d'énergie potentielle pour le métabolisme des entérocytes et pour l'animal. Ils contribuent de façon substantielle au fonctionnement des viscères (Scheppach 1994). Ils stimulent le développement des tissus intestinaux en agissant sur la prolifération des muqueuses. Ils agissent également sur la motricité intestinale. Les AGV, et principalement le butyrate, ont un effet stimulateur sur l'absorption d'eau, de minéraux dont le sodium, du glucose et d'acides aminés comme la glutamine. Le butyrate aurait des propriétés immunomodulatrices (Kalina et al 2002). nature de la flore et des substrats dispo-
Les AGV ont aussi un effet bactériostatique voire même bactéricide, variable selon le type d'acide et les bactéries, qui serait plus important que celui d'acides inorganiques tel que l'acide chlorhydrique (Thompson et Hinton 1997). Cet effet s'observe in vitro sur les bactéries à Gram négatif dans des conditions qui sont favorables à la présence de l'acide sous forme non dissociée $(\mathrm{pH}<\mathrm{pK}$ entre 4.75 et 4.81$)$, et si la durée de contact bactérie - acide est prolongée. Mais les formes non dissociées des AGV représentent seulement 1 à $6 \%$ des AGV dans les gammes de pH observées habituellement dans les contenus intestinaux ou caecaux, situés au dessus de 5,5 (figure 1). Cependant, in vivo, les AGV ont aussi un effet négatif sur la croissance de certaines bactéries, principalement les Entérobacteriaceae (Gram négatives) et, dans une moindre mesure, sur les entérocoques mais pas sur la croissance des lactobacilles (Wielen et al 2000).

Les AGV ont aussi des effets indésirables liés à leur influence bénéfique sur les bactéries pathogènes. Certains AGV peuvent augmenter la résistance à l'acidité des salmonelles et l'invasion cellulaire par ces bactéries, entraînant une augmentation de la colonisation de ces pathogènes dans les caeca (Van Immerseel et al 2003b, 2004).

Les bactéries produisent de l'ammoniac à partir des composés azotés d'origine alimentaire et urinaire. Une partie de cet ammoniac est utilisée par l'hôte pour la synthèse d'acides aminés non essentiels, mais c'est aussi un toxique cellulaire qui doit être dégradé en acide urique.

Les bactéries décarboxylent certains acides aminés conduisant à la formation d'amines (putrescine, spermidine, spermine). Ces amines qui stimulent la croissance de la muqueuse intestinale et l'absorption de nutriments peuvent

Tableau 5. Acides gras volatils le long du tube digestif du poulet (Zhang et al 2003) (1).

\begin{tabular}{|c|c|c|c|c|c|c|}
\hline \multirow[b]{2}{*}{ volatils } & \multicolumn{6}{|c|}{ Quantité ( $\mu \mathrm{g} / \mathrm{mL}$ de surnageant ; moyenne \pm SE) } \\
\hline & Jabot & Gésier & Duodénum & Jéjunum & lléon & Caeca \\
\hline Acétate & $848 \pm 144$ & $386 \pm 110$ & $210 \pm 27$ & $241 \pm 38$ & $594 \pm 100$ & $2856 \pm 270$ \\
\hline Propionate & $22 \pm 5$ & $20 \pm 4$ & $21 \pm 4$ & $38 \pm 21$ & $17 \pm 6$ & $154 \pm 48$ \\
\hline Butyrate & $15 \pm 5$ & $10 \pm 4$ & $11 \pm 5$ & $14 \pm 4$ & $39 \pm 7$ & $869 \pm 247$ \\
\hline Isobutyrate & $20 \pm 2$ & $8 \pm 2$ & $8 \pm 3$ & $9 \pm 2$ & $8 \pm 2$ & $69 \pm 15$ \\
\hline Valérate & $19 \pm 10$ & $10 \pm 5$ & $11 \pm 6$ & $15 \pm 3$ & $14 \pm 6$ & $91 \pm 27$ \\
\hline Isovalérate & $9 \pm 3$ & $10 \pm 2$ & $18 \pm 2$ & $13 \pm 3$ & $8 \pm 3$ & $81 \pm 27$ \\
\hline
\end{tabular}

(1) Poulets de chair (6 animaux de 50 à 55 j) à croissance rapide élevés au sol en conditions expérimentales (cage), consommant un régime composé de maïs, soja, farine de poisson et huile de soja, sans antibiotique. 
également avoir un effet négatif. Ainsi l'histamine, bien qu'étant beaucoup moins efficace que les cytokines, est impliquée dans la réaction inflammatoire.

\section{3 / Impact sur la physiologie digestive}

Les interactions entre la microflore et la muqueuse digestive entraînent des modifications de la structure et du fonctionnement du tube digestif (tableau 6). Cela a été observé avec un composant majeur de la flore commensale intestinale de la souris et de l'homme, Bacteroides thetaiotaomicron, qui module l'expression de gènes impliqués dans plusieurs fonctions intestinales importantes, telles que l'absorption de nutriments, la fonction de barrière de l'épithélium, le métabolisme des xénobiotiques, l'angiogenèse et la maturation intestinale (Hooper et al 2001). Les interactions entre la microflore et la muqueuse digestive sont à la fois symbiotiques et compétitives.

\section{1 / Modifications anatomiques et physiologiques du tractus digestif}

L'association des bactéries à la muqueuse intestinale et la production de différents métabolites entraînent des modifications anatomiques et physiologiques des cellules de la paroi intestinale et des muscles lisses (Coates 1980, Furuse et Okumura 1994). Ainsi le poids relatif de l'intestin grêle est plus élevé chez les animaux conventionnels que chez les animaux axéniques. Ceci est dû à l'augmentation de la longueur relative de l'intestin, et à l'épaississement de la paroi lié principalement aux tissus connectifs, en particulier la lamina propria. Chez l'oiseau conventionnel, les villosités intestinales sont plus

Tableau 6. Effet de la présence de flore digestive sur la physiologie digestive du poulet.

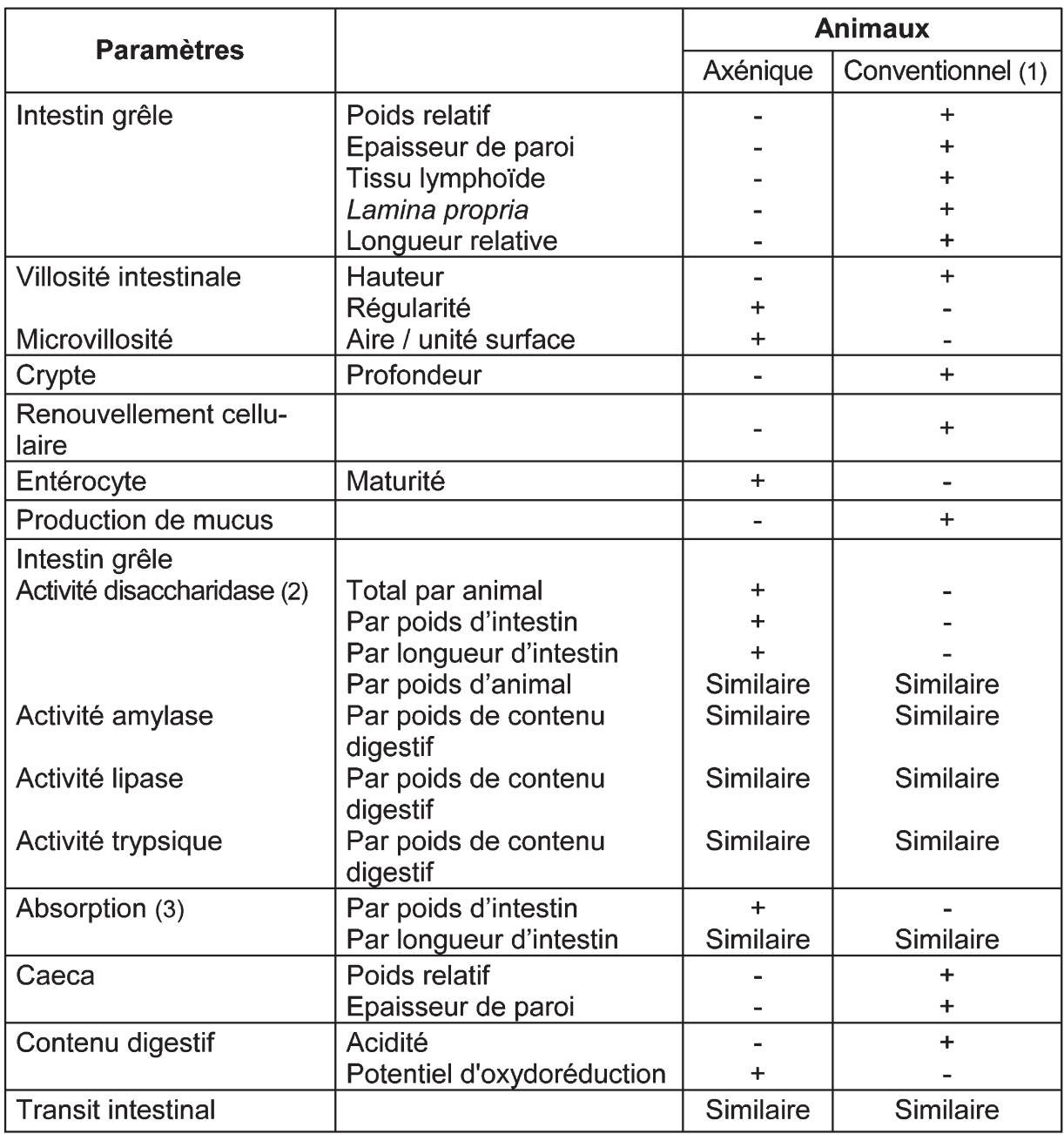

(1) Les poulets conventionnels ont un poids plus faible que les poulets axéniques.

(2) Maltase et saccharase.

(3) Méthionine et glucose. hautes dans le jéjunum et l'iléon et de forme moins régulière que chez l'oiseau axénique, mais l'aire développée par les microvillosités par unité de surface est plus faible. Les cryptes sont plus profondes tout le long de l'intestin grêle et le nombre de cellules en division est plus élevé conduisant à un renouvellement cellulaire accéléré du duodénum distal à l'iléon. Les entérocytes atteignent plus rapidement le haut des villosités, et présentent une plus faible maturité. Ainsi, l'activité totale (par g de tissus) des enzymes digestives intestinales telles que la maltase et la saccharase est moins élevée. Cependant, les activités de ces disaccharidases exprimées par poids d'animal sont similaires. La présence de flore ne modifierait pas l'activité d'autres enzymes impliquées dans la digestion, telles que l'amylase, la lipase ou la trypsine pancréatique dans les contenus de l'intestin grêle (Lepkowsky et al 1964, Philips et Fuller 1983). De même, l'absorption in vivo de nutriments tels que la méthionine et le glucose n'est pas modifiée (Yokota et Coates 1982).

Les caeca ont un poids relatif et une paroi plus épaisse en présence de micro-organismes (Furuse et Yokota 1984). Cependant, bien que les caeca soient les sites principaux de la flore digestive, très peu d'études ont été publiées sur les modifications de leur muqueuse par la flore. L'augmentation de la flore par l'introduction de lactose dans l'alimentation entraîne une diminution de l'épaisseur de la lamina propria et une augmentation de la prolifération cellulaire (Tellez et al 1993). Le temps de renouvellement cellulaire est plus court dans la partie distale des caeca par rapport à la partie proximale, probablement du fait de la présence importante de la flore dans cette zone (Takeuchi et al 1998).

En présence de flore, les contenus digestifs sont généralement plus acides et le potentiel d'oxydo-réduction plus faible que chez des animaux axéniques.

\section{2 / Production et hydrolyse du mucus}

La microflore entraîne une augmentation de la production de mucines (Sakata et Setoyam 1995) ainsi qu'une modification des proportions des différents types de glycoprotéines qui les constituent. Ces modifications pourraient s'effectuer de façon directe par la libération locale de facteurs bioactifs ou indirectement par 1'activation des cellules immunitaires de 
l'hôte (Deplancke et Gaskins 2001). Par ailleurs, les mucines pourraient être utilisées comme sources de carbone et d'énergie par certaines bactéries grâce à leurs activités glycosidiques.

\section{3 / Modification du transit intestinal}

Chez les oiseaux axéniques, aucune modification de transit intestinal ne se manifeste par rapport aux animaux conventionnels, contrairement aux mammifères de laboratoire, qui présentent un élargissement du caecum entraînant un ralentissement du transit (Coates 1980). Cependant, l'effet de la flore sur le transit pourrait dépendre du type de régime. Ainsi cet effet a été observé dans le cas de régimes contenant des matières premières riches en polysaccharides non amylacés hydrosolubles qui augmentent la viscosité des contenus digestifs (Nahashon et al 1994b).

\section{4 / Conséquences sur la valeur nutritionnelle de l'aliment}

\section{1 / Digestion des aliments}

Les micro-organismes sont en compétition avec l'hôte pour l'utilisation des aliments présents dans le tube digestif. En effet, ils possèdent un très grand nombre d'enzymes par rapport à leur hôte, et ceux qui se trouvent dans la lumière intestinale peuvent utiliser les constituants alimentaires avant l'hôte. Les aliments peu digestibles par l'hôte sont les plus concernés. Par ailleurs, dans le cas de régimes riches en polysaccharides non amylacés hydrosolubles, la flore est suspectée d'intervenir dans l'effet négatif observé sur la digestion des aliments (Langhout et al 2000), bien que ce rôle soit controversé (Maisonnier et al 2003).

Les micro-organismes du tube digestif auraient un effet positif en libérant des nutriments absorbables par l'hôte au niveau de l'intestin et des caeca, ces derniers possédant aussi des capacités de transport des glucides et des acides aminés (Moreto et Planas 1989).

Ainsi l'utilisation d'antibiotiques peut entraîner aussi bien une augmentation qu'une diminution de la digestibilité de l'aliment (Raharjo et Farrell 1984, Thomke et Elwinger 1998).

\section{a) Digestion des glucides}

Parmi les glucides, on distingue ceux que l'oiseau peut digérer (amidon, dextrines, oligosaccharides et monosaccharides) et ceux qu'il ne peut pas utiliser, tels que les polysaccharides non amylacés (cellulose, hémicellulose, substances pectiques).

Parmi les glucides digestibles par l'hôte, l'amidon de maïs ne présente pas de différence de digestibilité en présence de microflore (Kussaibati et al 1982a) bien que des micro-organismes soient capables de l'hydrolyser en particulier dans le jabot (Champ et al 1981).

Les glucides non digestibles sont fermentés par la microflore dans le jabot et principalement au niveau des caeca (Mead 1989). La microflore ne semble pas disposer d'enzymes capables d'hydrolyser la cellulose.

\section{b) Digestion des lipides}

Chez le jeune poulet de moins de trois semaines, la flore diminue la digestibilité apparente fécale des lipides d'origine végétale de 2 points et celles des graisses animales de 10 points (Boyd et Edwards 1967, Kussaibati et al 1982a). Cela provient en partie de l'excrétion endogène de lipides cellulaires liée à la desquamation des cellules de l'épithélium intestinal ainsi qu'à la présence de la biomasse bactérienne. Mais cette réduction de digestibilité provient surtout de la déconjugaison des sels biliaires par certaines espèces bactériennes en particulier les lactobacilles (Tannock et al 1989). Comme les sels biliaires conjugués servent à la formation des micelles, leur faible concentration réduit la solubilisation des lipides et donc leur absorption, en particulier ceux contenant des acides gras saturés à longue chaîne. Par conséquent, la digestibilité des acides gras saturés tels que l'acide palmitique et stéarique est fortement diminuée alors que celle des acides gras insaturés tels que l'acide oléique et linoléique n'est pas modifiée par la présence de microflore (Boyd et Edwards 1967).

\section{c) Digestion des protéines}

L'effet de la microflore sur la digestibilité des protéines est variable, probablement en raison de différences de composition des régimes alimentaires. Ainsi, Salter et Fulford (1974) n'observent pas de différence de digestibilité fécale apparente entre des animaux axéniques et conventionnels, alors que Kussaibati et al (1982a) observent une digestibilité plus faible chez les conventionnels. D'après Salter (1973) la microflore a un effet positif sur la digestion des protéines dans le cas des protéines de mauvaise qualité qui sont mal hydrolysées par l'hôte mais le sont en partie par la microflore. Cependant dans le cas de protéines très altérées par la chaleur, même la microflore ne peut les hydrolyser. Par ailleurs, la diminution de la digestibilité apparente causée par la microflore pourrait être due à l'augmentation de la production de protéines endogènes provenant du mucus, des débris cellulaires et de la biomasse microbienne (Kussaibati et al 1982a). Toutefois, la microflore utilisant aussi ces protéines endogènes, elle réduit aussi leur quantité (Salter 1973). Globalement, dans le cas d'une alimentation constituée de protéines très digestibles, la microflore a peu d'effet.

\section{2 / Métabolisme azoté et éner- gétique}

L'effet de la flore digestive sur le tube digestif a des conséquences sur le métabolisme global de l'animal. Bien que l'intestin représente une faible proportion du poids du corps, c'est un organe gros consommateur d'énergie et de protéines du fait de son renouvellement rapide (24-48h). L'augmentation de son développement induit par la flore digestive représente donc un coût supplémentaire pour l'animal.

\section{a) Métabolisme azoté}

La flore peut avoir un effet favorable. En effet, les composés azotés d'origine alimentaire et urinaire, comme l'acide urique, qui persistent dans les caeca, sont dégradés par les bactéries en AGV et en ammoniac qui sont absorbés (Braun et Campbell 1989, Braun 2003). Une partie de l'ammoniac est incorporée dans le glutamate qui est utilisé pour la synthèse de protéines ou de glucose. A l'inverse, les besoins en protéines des poulets conventionnels sont plus élevés que ceux des poulets axéniques. En présence d'une microflore digestive, la synthèse protéique est augmentée de $25 \%$ au niveau du foie (métabolisme et détoxification des produits bactériens) et de $45 \%$ au niveau de l'intestin, soit une augmentation de 6 à $8 \%$ des synthèses protéiques totales (Muramatsu et al 1987). Par ailleurs, avec un régime pauvre en énergie métabolisable (2 $800 \mathrm{kcal} / \mathrm{kg})$, la présence de microflore entraîne une diminution de l'utilisation des protéines. Ainsi les animaux conventionnels ont une moins bonne rétention protéique (protéine retenue / unité de temps) et un moins 
bon taux de rétention protéique (protéines retenues / protéines consommées) que des animaux axéniques (Furuse et Okumura 1994).

\section{b) Métabolisme énergétique}

La microflore affecte la teneur du régime en énergie métabolisable négativement (Kussaibati et al 1982b) ou positivement (Furuse et Okumura 1994). Le type d'alimentation modulant la flore serait à l'origine de ces différences. L'effet négatif de la flore s'explique par la diminution de la digestibilité des nutriments, en particulier ceux des lipides, aux pertes liées à la fermentation des glucides disponibles pour l'animal, et à l'augmentation des pertes endogènes. Elle a par ailleurs, un effet bénéfique lié aux fermentations des glucides non utilisés par l'hôte. Elle produit ainsi des AGV qui peuvent servir de source d'énergie pour l'animal, après absorption en particulier au niveau des caeca. Cependant, les estimations des apports énergétiques liés aux AGV sont très variables selon les auteurs (Jozefiak et al 2004).

La flore augmente les besoins énergétiques d'entretien (Furuse et Okumura 1994). Bien que le métabolisme intestinal soit augmenté du fait de la plus forte synthèse protéique, cette perte énergétique est faible. Cette augmentation des besoins énergétiques s'expliquerait par un détournement de l'énergie alimentaire par les bactéries et une consommation d'énergie pour détoxifier les nombreuses substances produites par la microflore.

Globalement la flore entraîne donc une augmentation des besoins énergétiques.

\section{3 / Minéraux et vitamines}

La microflore a un impact sur la nutrition minérale. Elle a un effet négatif sur l'absorption ou le transport du calcium absorbé par les tissus intestinaux (Smith et Soares 1984). Elle entraîne une augmentation des besoins en magnésium et phosphore. La flore diminue l'absorption du manganèse, mais elle est sans effet sur d'autres oligoéléments tels que le cuivre, le zinc et le fer (Henry et al 1987). En revanche, de par sa production d'AGV, elle facilite l'absorption des minéraux comme le sodium au niveau des caeca et du côlon (Braun 2003).

Les bactéries intestinales synthétisent des vitamines, mais seul l'acide folique serait disponible pour l'animal (Coates
1980). Par ailleurs, en présence de flore, les besoins en certaines vitamines comme l'acide pantothénique sont augmentés pour détoxifier les produits bactériens. De plus, les vitamines B sont moins bien absorbées in vitro par l'intestin de poulets conventionnels que par celui de poulets axéniques. Cependant ces résultats n'ont pas été confirmés in vivo. La flore pourrait également avoir un effet négatif sur l'absorption des vitamines liposolubles qui nécessitent des acides biliaires.

\section{4 / Impact sur l'environne- ment}

L'effet de la flore sur la digestion des aliments a des conséquences sur les quantités de nutriments éliminés dans les excreta. Ainsi, l'amélioration de l'efficacité alimentaire en présence d'AFC permet de diminuer les rejets. Par ailleurs, la flore peut moduler les quantités de gaz émis par les litières. Ainsi, l'utilisation d'AFC peut diminuer la quantité d'ammoniac suite à une plus faible humidité des excreta (Thomke et Elwinger 1998).

\section{5 / Rôle sur la santé de l'animal}

\section{1 / Protection contre les micro- organismes néfastes}

La première flore implantée s'oppose à l'installation d'une autre flore. Ce phénomène appelé «effet barrière», se met en place avant la maturité complète du système immunitaire du tube digestif et peut ainsi empêcher l'implantation de la microflore pathogène. Les travaux ont surtout porté sur les salmonelles, mais aussi sur Campylobacter spp., Yersinia, E. coli, Clostridium perfringens, Listeria, etc. Ainsi, il a été montré que la colonisation des caeca par les salmonelles est limitée par le traitement des poussins juste après éclosion avec une flore caecale de poulets adultes sains (Nurmi et Rantale 1973). L'utilisation de mélanges de nombreuses espèces bactériennes est plus efficace que les mélanges contenant peu d'espèces (Stavric et D'aoust 1993). De la même façon, les lactobacilles s'opposent à la croissance des coliformes (Fuller 1984). La microflore fécale de poulets sains protège des animaux conventionnels contre des souches d'E. coli pathogènes.

Les mécanismes à la base de cet effet barrière sont variés. Certaines bactéries bénéfiques créent un micro-environne- ment hostile aux autres espèces bactériennes en produisant des métabolites antimicrobiens comme des acides gras à chaîne courte, des bactériocines, ou des métabolites de l'oxygène. Elles modifient des récepteurs utilisés par les bactéries néfastes ou leurs toxines, empêchant ainsi leur développement dans le tube digestif. La flore bénéfique intervient aussi par l'utilisation compétitive de nutriments essentiels. La stimulation du système immunitaire serait aussi impliquée.

\section{2 / Stimulation du système immunitaire}

La flore intestinale participe au développement et au maintien d'un système immunitaire intestinal efficace (Salminen et al 1998). Elle joue un rôle dans le développement et la régulation de la réponse immunitaire en influençant le nombre, la distribution et le degré d'activation des populations cellulaires du système immunitaire intestinal. Elle représente une source majeure de stimuli antigéniques pour la maturation et la migration des cellules lymphoïdes présentes dans les plaques de Peyer. Ces organes lymphoïdes secondaires sont constitués d'agrégats organisés de follicules lymphoïdes disséminés à la surface externe de l'intestin des mammifères et des oiseaux, bien que répartis différemment et recouvrant une surface plus faible chez ces derniers (Muir et al 2000). Les plaques de Peyer constituent le lieu privilégié d'interactions entre les cellules présentatrices d'antigènes provenant de la muqueuse intestinale et les lymphocytes provenant de la moelle osseuse (Kato et Owen 1999). Le sommet des plaques de Peyer est plus accessible aux microorganismes que le reste de la surface de l'intestin du fait d'un nombre réduit de cellules en gobelet sécrétrices de mucus, et de la présence de cellules M (microfold) capables de transporter efficacement les antigènes solubles et les micro-organismes vers les tissus lymphoïdes sous-jacents.

Les mécanismes par lesquels les bactéries stimulent le système immunitaire font actuellement l'objet de spéculations. Lors d'un contact avec un antigène, et sous l'effet d'une stimulation non spécifique par les micro-organismes, les cellules dendritiques migrent vers les plaques de Peyer ou les ganglions sous-jacents pour initier une réponse spécifique entraînant l'activation des lymphocytes. Ceux-ci vont sortir des ganglions et, in fine, retourner vers la muqueuse digestive où ils vont accom- 
plir leurs fonctions : cytotoxicité et production d'immunoglobulines secrétoires. Ces IgA sont adaptées à la protection des muqueuses (résistance à la protéolyse intraluminale, pas d'activation du complément ou de la réponse inflammatoire) et font partie de la première ligne de défense face à un antigène étranger. Elles ont une faible affinité et une large spécificité. La fonction principale de ces immunoglobulines est, en coopération avec des mécanismes de défense moins spécifiques, de protéger l'hôte contre les éléments susceptibles d'altérer l'intégrité de l'épithélium intestinal en neutralisant les toxines microbiennes. Ces immunoglobulines permettent d'empêcher la pénétration des bactéries commensales à travers l'épithélium intestinal. Leur production est indépendante des cellules $\mathrm{T}$ et des tissus lymphoïdes organisés (Macpherson et al 2000).

L'initiation d'une réponse spécifique à partir des organes lymphoïdes secondaires ne se produit que lorsqu'un antigène étranger a traversé la muqueuse et est parvenu au niveau des ganglions drainants. Cette réponse spécifique va impliquer un grand nombre de médiateurs comme les cytokines inflammatoires et les chimiokines qui vont conduire à l'activation et au recrutement de lymphocytes cytotoxiques, de plasmocytes à $\mathrm{IgA}, \mathrm{IgG}$ ainsi que des cellules régulatrices (Salminen et al 1998).

Les bactéries stimulent l'immunité innée en activant la phagocytose et la synthèse de cytokines par les macrophages (Moreau et Gaboriau-Routhiau 2000). Or, ces derniers régulent la réponse inflammatoire qui doit être fonctionnelle sans être excessive. Les cytokines peuvent modifier le métabolisme de l'animal et entraîner une augmentation du catabolisme protéique et une réduction de la masse musculaire (Klasing et al 1991). Elles détournent ainsi les acides aminés provenant des muscles et de l'alimentation vers le foie pour synthétiser des protéines de la phase aiguë (inflammation) et la néoglucogénèse. Des acides aminés sont aussi utilisés pour la synthèse des différents composants du système immunitaire (cellules, Ig, cytokines). Les cytokines entraînent aussi une hyperlipidémie et affectent le métabolisme minéral. Cette activation continue du système immunitaire par la flore digestive conduit à la réduction des performances zootechniques (Klasing et al 1991). Cependant, les bactéries peuvent aussi atténuer la réponse inflammatoire (Neish et al 2000).
La flore digestive module aussi la réponse immunitaire spécifique au niveau local et systémique (Salminen et al 1998). En particulier, la tolérance orale aux antigènes alimentaires et bactériens peut être profondément modifiée par la flore commensale (Moreau et Gaboriau-Routhiau 2000). La flore digestive intervient aussi dans la modulation de la réponse immunitaire contre les pathogènes.

Les bactéries intestinales ont des propriétés immunomodulatrices différentes suivant les espèces (Maassen et al 1998), liées probablement à la composition de leur paroi cellulaire (Herich et Levkut 2002). Aussi, les conséquences sur la réponse immunitaire de l'animal dépendent de la composition de la flore.

\section{3 / Développement de patholo- gies}

Les fermentations par la flore digestive, en particulier des acides aminés contenus dans les litières, s'accompagnent de la production de composants irritants comme l'ammoniac, entraînant des conjonctivites et des problèmes respiratoires chez l'animal (Thomke et Elwinger 1998). D'autre part, l'utilisation d'AFC a souvent été rapportée comme réduisant l'humidité dans les excreta, avec des conséquences favorables sur la santé des volailles : réduction des problèmes de pattes, limitation du développement de pathogènes dans les litières.

\section{6 / Conséquences pour les productions animales}

\section{1 / Croissance}

Les animaux conventionnels ont généralement une moins bonne croissance que les animaux axéniques tout en ayant une consommation similaire (Kussaibati et al 1982a, Furuse et Okumura 1994). Plusieurs facteurs déjà évoqués précédemment expliquent cette dégradation. Tout d'abord, chez les animaux conventionnels, la digestion est réduite, en particulier celle des lipides. De plus, les micro-organismes détournent des glucides et des protéines de la ration pour satisfaire leurs propres besoins au détriment de l'hôte. Enfin, l'augmentation du développement de l'intestin et du renouvellement des entérocytes ainsi que la stimulation du système immunitaire, détournent des nutriments aux dépens du dépôt musculaire.

Cet effet négatif sur la croissance est lié à la présence de certains microorganismes. Ainsi deux types bactériens faisant partie de la flore courante des caeca ont été incriminés : Streptococcus faecium (ou Enterococcus hirae) et Clostridium perfringens (Fuller 1984).

\section{2 / Qualités des produits}

La microflore intestinale peut avoir des effets aussi bien sur la qualité bactériologique des produits que sur leur composition et leurs qualités organoleptiques.

La contamination de la carcasse au moment de l'abattage par les bactéries du tractus digestif affecte la qualité sanitaire des produits avicoles. Ainsi, on peut trouver Salmonella, Campylobacter spp., Helicobacter pullorum, Listeria spp., Clostridium perfringens, Yersinia et Hafnia. Ces bactéries présentent un danger aussi bien pour l'animal que pour l'homme comme dans le cas des Salmonelles, ou uniquement chez l'homme comme Campylobacter jejuni.

La composition et la qualité organoleptique de la viande et de l'œuf sont modifiées par la flore digestive. En ce qui concerne la viande, certains probiotiques augmentent sa teneur en protéines et diminuent sa teneur en lipides dont le cholestérol (Wambeke et Peters 1995, Haddadin et al 1996). La flore intestinale a un effet sur la flaveur de la viande (Harris et al 1968, Mead et al 1983). Le cas des volailles consommées après faisandage est un excellent exemple. Ce mode de maturation de la viande entraîne le développement de flaveurs qui seraient liées en partie à la microflore digestive (Barnes 1979). Des composants des flaveurs, originaires de la flore intestinale, seraient transférés de l'intestin vers le muscle.

La surface de l'œuf, ainsi que son contenu sont modifiés par les changements de microflore intestinale liés à l'utilisation d'antibiotiques ou de probiotiques. Certains probiotiques augmentent l'épaisseur de la coquille (à poids d'œuf identique), sa teneur en calcium, ainsi que sa résistance (Mohan et al 1995, Tortuero et Fernandez 1995, Panda et al 2000). Le contenu de l'œuf est modifié dans sa composition, son aspect et son goût. Ainsi, la qualité de l'albumen de l'œuf (hauteur du blanc 
épais) est améliorée par l'ajout de certains probiotiques (Nahashon et al 1994a). La présence de flore entraîne une modification de la composition en acides gras du jaune d'œuf (Furuse et Okumura 1994). Sa teneur en cholestérol est réduite par l'utilisation de certains probiotiques (Mohan et al 1995). Le mauvais goût des jaunes des œufs à coquille colorée, observé en présence des matières premières critiques alimentaires telles que le colza ou la farine de poisson, est dû aux bactéries de la flore intestinale à Gram positif qui transforment la choline en trimethylamine (Sauveur et de Reviers, 1988).

\section{7 / Contrôle de la micro-} flore (figure 4)

Dans le cadre de la recherche d'alternatives aux AFC, de nombreuses solutions ont été proposées aussi bien au niveau de la gestion sanitaire et hygiénique des élevages, qu'au niveau de l'alimentation.

Dans le premier cas, le développement de la microflore néfaste peut être limité en gérant au mieux l'hygiène et les conditions d'élevage, l'aménage- ment des bâtiments, et en pratiquant un vide sanitaire.

Au niveau nutritionnel, de nombreuses alternatives ont été proposées. Tout d'abord l'hygiène doit être contrôlée de la réception de la matière première jusqu'à la livraison de l'aliment, en vue de limiter l'apport de flores exogènes. Par ailleurs, la granulation et l'utilisation d'acides organiques permettent de réduire la charge bactérienne dans l'aliment. Des traitements technologiques appropriés peuvent augmenter la digestibilité limitant ainsi les substrats disponibles pour la microflore. Ce der-

Figure 4. Possibilités de contrôle de la flore digestive et de ses effets.

Gestion sanitaire et hygiénique des élevages

Hygiène et conditions d'élevage

Aménagement des bâtiments

Vide sanitaire

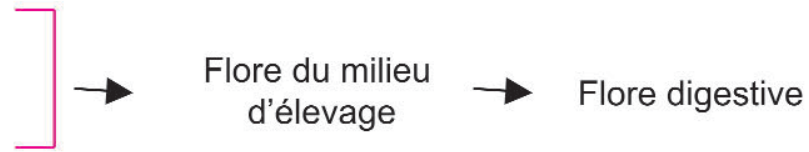

\section{Alimentation}

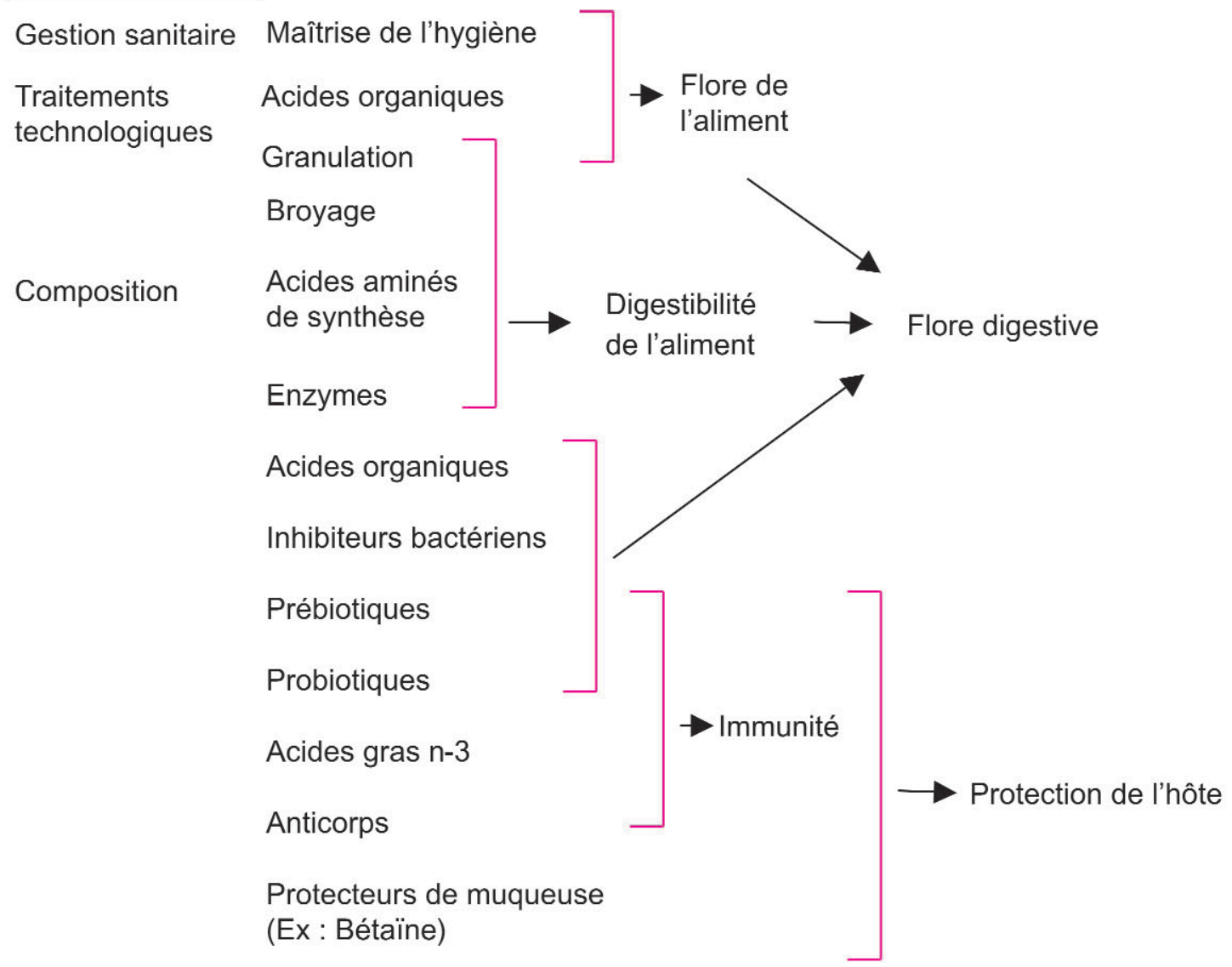


nier objectif peut aussi être atteint en équilibrant au mieux les formules alimentaires avec des acides aminés de synthèse. Des enzymes peuvent être ajoutées pour hydrolyser les composants alimentaires et les rendre plus facilement disponibles pour l'hôte, ou hydrolyser les composants peu digestibles utilisés comme substrats par les micro-organismes.

L'hôte peut être protégé contre l'action néfaste de certaines bactéries. Ainsi des substances naturelles, comme la bétaïne, peuvent être utilisées pour protéger la muqueuse intestinale. L'immunité intestinale peut être améliorée par la voie alimentaire en utilisant des acides gras n-3, des prébiotiques, des probiotiques, ou des anticorps (Godderis et al 2002, Van Immerseel et al 2003a).

La microflore ou son action peuvent être contrôlées. Ainsi, on utilise dans l'aliment ou l'eau de boisson des acides organiques qui ont un effet toxique sur les bactéries. L'activité d'enzymes microbiennes néfastes à l'hôte comme celles hydrolysant les acides biliaires, pourrait être bloquée avec des inhibiteurs. D'autres molécules telles que la lactoferrine pourraient être utilisées comme inhibiteurs bactériens (Kim et al 2002). La microflore est modifiable en utilisant des prébiotiques et des probiotiques qui ont été particulièrement étudiées ces dernières années. Par exemple dans le cas des probiotiques qui sont des préparations définies de micro-organismes vivants administrées en continu, les Lactobacilles sont les plus étudiées. Certaines souches sont particulièrement intéressantes, comme Lactobacillus salivarius mais elle est sensible à la température lors de la granulation des aliments ou Lactobacillus reuteri du fait de la production d'une toxine, la réutérine. Cependant, les résultats obtenus en utilisant des prébiotiques ou des probiotiques sont très variables. Les effets de la modification de la flore dépendent de très nombreux facteurs : espèces et souches bactériennes, quantités utilisées, additifs présents dans le probiotique (acides aminés, vitamines), alimentation, animaux cibles (espèce, souche, âge), conditions d'élevage. Ainsi, bien que de nombreuses études concluent à un effet bénéfique, d'autres ne montrent aucun effet de la modification de la microflore, voire des effets négatifs. De plus les travaux publiés ne sont pas représenta- tifs de l'ensemble des études effectuées car beaucoup sont restées confidentielles. Par ailleurs, une modification de la flore peut avoir à la fois des effets bénéfiques et des effets néfastes.

\section{Conclusions}

La flore intestinale a des effets sur l'animal à de nombreux niveaux. L'objectif est de pouvoir bénéficier de ses effets positifs comme l'effet barrière, le développement et la modulation du système immunitaire, tout en minimisant ses effets négatifs comme le coût métabolique qu'elle induit du fait du développement plus important de l'intestin et d'un système immunitaire activé en permanence. Ces effets négatifs et positifs varient selon la composition de la flore qui elle même varie en fonction de nombreux paramètres. Il s'agit d'un équilibre complexe qu'il est nécessaire de mieux connaître pour pouvoir à l'avenir orienter la flore dans un but bénéfique pour l'animal, le système de production et pour la santé du consommateur.

\section{Références}

Apajalahti J., Kettunen A., Bedford M., Holben W., 2001. Percent $\mathrm{G}+\mathrm{C}$ profiling accuratly reveals diet-related differences in the gastrointestinal microbial community of broiler chickens. Appl. Environ. Microbiol., 67, 5656-5667.

Apajalahti J., Kettunen A., Graham H., 2004. Characteristics of the gastrointestinal microbial communities, with special reference to the chicken. World's Poult. Sci. J., 60, 223-232.

Barnes E.M., 1979. The intestinal microflora of poultry and game birds during life and after storage. J. Appl. Bacteriol., 46, 407-419.

Boyd F.M., Edwards H.M., 1967. Fat absorption by germ-free chicks. Poult. Sci., 46, 14811483

Braun E.J., 2003. Regulation of renal and lower gastrointestinal function: role in fluid and electrolyte balance. Comp. Biochem. Physiol. A. Mol. Integr. Physiol., 136, 499-505.

Braun E.J., Campbell C.E., 1989. Uric acid decomposition in the lower gastrointestinal tract. J. Exp. Zool., 3, 70-74.

Broom M.F., Sherriff R.M., Ferry D.M., Chadwick V.S., 1993. Formylmethionylleucylphenylalanine and the SOS operon in Escherichia coli: a model of host-bacterial interactions. Biochem. J., 291, 895-900.

Champ M., Szylit O., Gallant D.J., 1981. The influence of microflora on the breakdown of maize starch granules in the digestive tract of chicken. Poult. Sci., 60, 179-187.
Coates M.E., 1980. The gut microflora and growth. In: Growth in animals. (Ed) T.L.J, Lawrence. Butterworths, London, UK, 175-188.

Deplancke B., Gaskins H.R., 2001. Microbial modulation of innate defense: goblet cells and the intestinal mucus layer. Am. J. Clin. Nutr., 73, 1131-1141 S.

Engberg R.M., Hedemann M.S., Jensen B.B., 2002. The influence of grinding and pelleting of feed on the microbial composition and activity in the digestive tract of broiler chickens. Br. Poult. Sci., 43, 569-579.

Engberg R.M., Hedemann M.S., Steenfeldt S., Jensen B.B., 2004. Influence of whole wheat and xylanase on broiler performance and microbial composition and activity in the digestive tract. Poult. Sci., 83, 925-938.

Farner D. S., 1942. The hydrogen ion concentration in avian digestive tracts. Poult. Sci., 21, 445-450.

Fuller R., 1984. Microbial activity in the alimentary tract of birds. Proc. Nutr. Soc., 43, 55-61.

Furuse M., Okumura J., 1994. Nutritional and physiological characteristics in germ-free chickens. Comp. Biochem. Physiol., 109A, 547-556.

Furuse M., Yokota H., 1984. Effect of the gut microflora on the size and weight of organs of chicks fed diets of different protein content. Br. Poult. Sci., 25, 429-439.

Gabriel I., Mallet S., Leconte M., Fort G., Naciri M., 2003. Effects of whole wheat feeding on the development of coccidial infection in broiler chickens. Poult. Sci., 82, 1668-1676.

Goddeeris B.M., Boersma W.J.A., Cox E., Stede Y.V.D., Koenen M.E., Vancaeneghem S., Mast J., Broeck W.V.D., 2002. The porcine and avian intestinal immune system and its nutritional modulation. In: Nutrition and health of the gastrointestinal tract. (Eds) M.C. Blok, H.A. Vahl, L. de Lange, A.E. van de Braak, G. Hemke, M. Hessing. Academic Publishers, Wageningen, 97134.

Gong J., Forster R.J., Yu H., Chambers J.R., Wheatcroft R., Sabour P.M., Chen S., 2002. Molecular analysis of bacterial populations in the ileum of broiler chickens and comparison with bacteria in the cecum. FEMS Microbiol. Ecol., 41, 171-179.

Haddadin M.S.Y Abdulrahim S.M. Hashlamoun E.A.R., Robinson R.K., 1996. The effect of Lactobacillus acidophilus on the production and chemical composition of hen's eggs. Poult. Sci., 75, 491-494.

Harris N.D., Strong D.H., Sunde M.L., 1968. Intestinal flora and chicken flavor. J. Food Sci., $33,543-547$.

Henry P.R., Ammerman C.B., Campbell D.R., Miles R.D., 1987. Effect of antibiotics on tissue trace mineral concentration and intestinal tract weight of broiler chicks. Poult. Sci., 66, 1014-1018.

Herich R., Levkut M., 2002. Lactic acid bacteria, probiotics and immune system. Vet. Med., 47, 169-180. 
Hooper L.V., Wong M.H., Thelin A., Hansson L., Falk P.G., Gordon J.I., 2001. Molecular analysis of commensal host-microbial relationships in the intestine. Science, 291, 881-884.

Jansman A.J.M., van der Klis J.D., Lemme A., Petri A., 2003. Effects of dietary protein content and ingredient composition on the growth performance and microbial activity in the digestive tract of broilers. WPSA, 14th European Symposium of Poultry Nutrition. Lillehammer, Norvège, 10-14 août 2003, 172-173.

Jin L.Z., Ho Y.W., Abdullah N., Ali M.A., Jalaludin S., 1998. Effects of adherent Lactobacillus cultures on growth, weight of organs and intestinal microflora and volatile fatty acids in broilers. Anim. Feed Sci. Technol., 70, 197-209.

Jozefiak D., Rutkowski A., Martin, S.A., 2004. Carbohydrate fermentation in the avian ceca: a review. Anim. Feed Sci. Technol., 113, 1-15.

Kalina U., Koyama N., Hosoda T., Nuernberger H., Sato K., Hoelzer D., Herweck F., Manigold T., Singer M.V., Rossol S., Bocker U., 2002. Enhanced production of IL-18 in butyrate-treated intestinal epithelium by stimulation of the proximal promoter region. Eur. J. Immunol., 32, 2635-2643.

Kato T., Owen R.L., 1999. Structure and function of intestinal epithelium. In: Mucosal immunology. (Eds) P.L. Ogra, J. Mestecky, M. E. Lamm . Academic Press, London, 115-132.

Kim W.S., Tanaka T., H., K., Shimazaki K., 2002. Lactoferrin-binding proteins in Bifidobacterium bifidum. Biochem. Cell Biol., 80, 91-94.

Kimura N., Mimura F., Nishida S., Kobayashi A., Mitsuoka T., 1976. Studies on the relationship between intestinal flora and cecal coccidiosis in chicken. Poult. Sci., 55, 1375-1383.

Klassing K.C., Johnstone B.J., Benson B.N., 1991. Implications of an immune response on growth and nutrient requirements of chicks. In: Recent advances in animal nutrition. W. Haresign and D.J.A. Cole. ButterworthHeinemann Ltd (Eds), Oxford, 135-146.

Knarreborg A., Simon M.A., Engberg R.M., Jensen B.B., Tannock G.W., 2002. Effects of dietary fat source and subtherapeutic levels of antibiotic on the bacterial community in the ileum of broiler chickens at various ages. Appl. Environ. Microbiol., 68, 5918-5924.

Kussaibati R., Guillaume J., Leclercq B., 1982a. The effect of gut microflora on the digestibility of starch and proteins in young chicks. Ann. Zootech., 31, 483-488.

Kussaibati R., Guillaume J., Leclercq B., Lafont J.P., 1982b. Effect of the intestinal microflora and added bile salts on the metabolisable energy and digestibility of saturated fats in the chicken. Arch. Geflügelkd., 46, 42-46.

Lan P.T., Hayashi H, Sakamoto, M., Benno Y, 2002. Phylogenetic analysis of cecal microbiota in chicken by the use of $16 \mathrm{~S}$ rDNA clone libraries. Microbiol. Immunol., 46, 371-382.

Langhout D. J., Schutte J. B. de Jong J., Sloetjes H., Verstegen M. W. A., Tamminga S., 2000. Effect of viscosity on digestion of nutrients in conventional and germ-free chicks. Br. J. Nut., 83, 533-540.

Lepkovsky S., Wagner M., Furuta F., Ozine K., Koike T., 1964. The proteases, amylase and lipase of the pancreas and intestinal contents of germfree and conventional chicken. Poult. Sci., $43,722-726$.
Lu J., Idris U., Harmon B., Hofacre C., Maurer J., Lee M.D., 2003. Diversity and succession of the intestinal bacterial community of the maturing broiler chicken. Appl. Environ. Microbiol., 69, 6816-6824.

Maassen C.B.M., Holten J.C.A.M.V., Balk F., Bak-Glashouwer M.J.H.D., Leer R., Laman J.D., Boersma W.J.A., Claassen E., 1998. Orally administered Lactobacillus strains differentially affect the direction and efficacy of the immune response. Vet. Quarterly, 20, S3, S81-S83.

Macpherson A.J., Gatto D., Sainsburry E. Harriman G.R., Hengartner H., Zinkernagel R.M., 2000. A primitive T-cell-independent mechanism of intestinal mucosal IgA responses to commensal bacteria. Science, 288, 22222226.

Maisonnier S., Gomez J., Bree A., Berri C., Baeza E., Carré B., 2003. Effects of microflora status, dietary bile salts and guar gum on lipid digestibility, intestinal bile salts and histo-morphology, in broiler chickens. Poult. Sci., 82, 805814.

Mallet S., Bouvarel I., Lessire M., 2001. Facteurs de variation de la microflore intestinale des oiseaux domestiques : impact de l'alimentation. 4e Journ. Rech. Avicoles. Nantes, France, 27-29 mars, 159-164.

Mathlouthi N., Mallet S., Saulnier L., Quemener B., Larbier M., 2002. Effects of xylanase and b-glucanase addition on performance, nutrient digestibility, and physico-chemical conditions in the small intestine contents and caecal microflora of broiler chickens fed a wheat and barley-based diet. Anim. Res., 51, 395-406.

Mead G.C., 1989. Microbes of the avian cecum. Types present and substrates utilized. J. Exp. Zool., 3, suppl, 48-54.

Mead G.C., Griffiths N.M., Impey C.S., Coplestone J.C., 1983. Influence of diet on the intestinal microflora and meat flavour of intensively-reared broiler chickens. Br. Poult. Sci., 24, 261-272.

Mohan B., Kadirvel R., Bhaskaran M., Natarajan A., 1995. Effect of probiotic supplementation on serum/yolk cholesterol and on egg shell thickness in layers. Br. Poult. Sci., 36, 799 803.

Moreau M.C., Gaboriau-Routhiau V., 2000. Influence of resident intestinal microflora on the development and functions of the intestinalassociated lymphoid tissue. In: Probiotics 3: Immunomodulation by the gut microflora and probiotics. (Eds) R. Fuller, G. Perdigon. Kluwer academic publishers, Dordrecht, 69-114.

Moreto M., Planas J.M., 1989. Sugar and amino acid transport properties of the chicken caeca. J. Exp. Zool., 3 , suppl, 111-116.

Muir W.I., Bryden W.L., Husband A.J., 2000. Immunity, vaccination and the avian intestinal tract. Develop. Comp. Immunol., 24, 325-342.

Muramatsu T., Takasu O., Furuse M., Tasaki I., Okumura J., 1987. Influence of the gut microflora on protein synthesis in tissues and in the whole body of chicks. Biochem. J., 246, 475479.

Nahashon S.N., Nakaue H.S., Mirosh L.W., 1994a. Production variables and nutrient retention in single comb White Leghorn laying pullets fed diets supplemented with direct-fed microbials. Poult. Sci., 73, 1699-1711.

Nahashon S.N., Nakaue H.S., Snyder S.P., Mirosh L.W., 1994b. Performance of single comb White Leghorn layers fed corn-soybean meal and barley-corn-soybean meal diets supplemented with a direct-fed microbial. Poult. Sci., 73, 1712-1723.

Neish A.S., Gewirtz A.T., Zeng H., Young A.N. Hobert M.E., Karmali V., Rao A.S. Madara J.L., 2000. Prokaryotic regulation of epithelial responses by inhibition of I kappa Balpha ubiquitination. Science, 289, 1560-1563.

Nurmi, E., Rantale, M., 1973. New aspects of Salmonella infection in broiler production. Nature, 241, 210-211.

Orban J.I., Patterson J.A., Sutton A.L., Richards G.N., 1997. Effect of sucrose thermal oligosaccharide caramel, dietary vitamin-mineral level, and brooding temperature on growth and intestinal bacterial populations of broiler chickens. Poult. Sci., 76, 482-490.

Panda A.K., Reddy M.R., Ramarao S.V., Praharaj N.K., 2000. Effect of dietary supplementation of probiotic on performance and immune response of layers in the decline phase of production. Indian J. Poult. Sci. 35, 102-104.

Philips S.M., Fuller R., 1983. The activities of amylase and a trypsin like protease in the gut contents of germ-free and conventional chickens. Br. Poult. Sci., 24, 115-121.

Piard J.C., Desmazeaud M., 1991. Inhibiting factors produced by lactic acid bacteria. 1. Oxygen metabolites and catabolism endproducts. Lait, 71, 525-541.

Raharjo Y.C., Farrell D.J., 1984. Effects of cæcectomy and dietary antibiotics on the digestibility of dry matter and amino acids in poultry feeds determined by excreta analysis. Aust. J. Exp. Agric. Anim. Husb., 24, 516-521.

Sakata T., Setoyam H., 1995. Local stimulatory effect of short chain fatty acids on the mucus release from the hindgut mucosa of rats (Rattus norvegicus). Comp. Biochem. Physiol. A. Physiol., 111, 429-432.

Salminen S., Bouley C., Boutron-Ruault M.C., Cummings J.H., Franck A., Gibson G.R., Isolauri E., Moreau M.C., Roberfroid M., Rowland I., 1998. Functional food science and gastrointestinal physiology and function. Br. J. Nutr., 80, S147-171.

Salter D.N., 1973. The influence of gut microorganisms on utilization of dietary protein. Proc. Nutr. Soc., 32, 65-71.

Salter D.N., Fulford R.J., 1974. The influence of the gut microflora on the digestion of dietary and endogenous proteins: studies of the amino acid composition of the excreta of germ-free and conventional chicks. Br. J. Nutr., 32, 625-637.

Sauveur B., de reviers M., 1988. Qualité de l'oeuf. In : Reproduction des volailles et production d'oeufs. B. Sauveur (Ed), INRA, Paris, France, 377-436.

Scheppach W., 1994. Effects of short chain fatty acids on gut morphology and function. Gut, $35, \mathrm{~S} 35-\mathrm{S} 38$.

Smith H.W., 1965. Observations on the flora of the alimentary tract of animals and factors affecting its composition. J. Pathol. Bacteriol. 89, 95-122.

Smith J.C., Soares J.H., 1984. Minerals. In The germ-free animal in biomedical research. (Eds) M.E. Coates, B. Gustafsson. Laboratory Animals handbooks, London, UK, 275-284.

Stavric S., D'Aoust J.Y., 1993. Undefined and defined bacterial preparations for the competitive exclusion of Salmonella in poultry - a review. J. Food Prot., 56, 173-180. 
Suzuki K., Kodam Y., Mitsuoka T., 1989. Stress and intestinal flora. Bifidobact. Microflora, 8, 23-38

Takeuchi T., Kitagawa H., Imagawa T., Uehara M., 1998. Proliferation and cellular kinetics of villous epithelial cells and M cells in the chicken caecum. J. Anat., 193, 233-239.

Tannock G.W., Dashkevicz M.P., Feighner S.D., 1989. Lactobacilli and bile salt hydrolase in the murine intestinal tract. Appl. Environ. Microbiol., 55, 1848-1851.

Tellez G., Dean C.E., Corrier D.E., Deloach J.R., Jaeger L., Hargis B.M., 1993. Effect of dietary lactose on cecal morphology, pH, organic acids, and Salmonella enteritidis organ invasion in Leghorn chicks. Poult. Sci., 72, 636-642.

Thomke S., Elwinger K., 1998. Growth promotants in feeding pigs and poultry. I. Growth and feed efficiency responses to antibiotic growth promotants. Ann. Zootech., 47, 85-91.

Thompson J.L., Hinton M., 1997. Antibacterial activity of formic acid and propionic acid in the diet of hens on Salmonellas in the crop. Br. Poult. Sci., 38, 59-65.

Tortuero F., Fernandez E., 1995. Effects of inclusion of microbial cultures in barley-based diets fed to laying hens. Anim. Feed Sci. Technol., 53, 255-265.
Van Immerseel F., De Buck J., Pasmans F., Haesebrouck F., Ducatelle R., 2003a. Stratégies nutritionelles pour réduire les agents pathogènes chez les volailles. 5e Journ. Rech. Avicole. Tours, France, 26-27 mars, 141-148.

Van Immerseel F., De Buck J., Pasmans F., Velge P., Bottreau E., Fievez V., Haesebrouck F., Ducatelle R., 2003b. Invasion of Salmonella enteritidis in avian intestinal epithelial cells in vitro is influenced by short-chain fatty acids. Int. J. Food Microbiol., 85, 237-248.

Van Immerseel F., Fievez V., de Buck J., Pasmans F., Martel A., Haesebrouck F. Ducatelle R., 2004. Microencapsulated shortchain fatty acids in feed modify colonization and invasion early after infection with Salmonella enteritidis in young chickens. Poult. Sci., 83, 69-74.

Wambeke F.V., Peeters J., 1995. The effect of Paciflor(R) on the performances, carcass composition and caecal bacterial numbers of broilers. Arch. Geflugelkd., 59, 125-129.

Weurding R.E., 2002. Kinetics of starch digestion and performance of broiler chickens. Thèse Université de Wageningen.

Wielen P.W.J.J.V.D., Biesterveld S., Notermans S. Hofstra H., Urlings B.A.P. Knapen F.V., 2000. Role of volatile fatty acids in development of the cecal microflora in broiler chickens during growth. Appl. Environ. Microbiol., 66, 2536-2540.

Xia M.S., Hu C.H., Xu Z.R., 2004. Effects of copper-bearing montmorillonite on growth performance, digestive enzyme activities, and intestinal microflora and morphology of male broilers. Poult. Sci., 83, 1868-1875.

Yokota H., Coates M.E., 1982. The uptake of nutrients from the small intestine of gnotobiotic and conventional chicks. Br. J. Nutr., 47, 349356.

Zhang W.F., Li D.F., Lu W.Q., Yi G.F., 2003. Effects of isomalto-oligosaccharides on broiler performance and intestinal microflora. Poult Sci., 82, 657-663.

Zhu X.Y., Zhong T., Pandya Y., Joerger R.D., 2002. 16S rRNA-based analysis of microbiota from the caecum of broiler chickens. Appl. Environ. Microbiol., 68, 124-137.

Zoetendal E.G., Akkermans A.D.L., Akkermans-van Vliet W.M., deVisser J.A.G.M. deVos W.M., 2001. The host genotype affects the bacterial community in the human gastrointestinal tract. Microb. Ecol. Health Dis., 13, 129-134.

\section{Résumé}

La flore digestive des oiseaux reste incomplètement connue compte tenu des méthodes utilisées jusqu'à présent. Elle se trouve principalement dans le jabot et les caeca, mais aussi, bien que numériquement moins importante, dans l'intestin. Dans la partie supérieure du tube digestif, les bactéries anaérobies facultatives dominent, alors que les caeca hébergent surtout des bactéries anaérobies strictes. Cette microflore dépend de nombreux facteurs tels que l'individu, son âge, son environnement, et son alimentation. Elle est responsable de la production de différents métabolites qui peuvent être utiles ou nuisibles à l'hôte. Les interactions entre la microflore et la muqueuse intestinale sont à l'origine de nombreuses modifications structurales et fonctionnelles du tube digestif. La microflore entraîne une baisse de la digestibilité des lipides riches en acides gras saturés et peut modifier la digestion des glucides et des protéines. Elle entraîne une augmentation des besoins énergétiques et en acides aminés. Elle a un impact négatif sur la nutrition vitaminique. La flore indigène peut avoir un effet protecteur contre les micro-organismes néfastes et est responsable en partie du développement du système immunitaire intestinal. Globalement la présence d'une flore affecte négativement la croissance. Elle peut aussi avoir des effets sur la qualité des produits animaux (viande, œuf). Une connaissance plus approfondie de la microflore et de ses effets permettra à l'avenir de mieux la contrôler pour l'orienter dans un but bénéfique aussi bien pour l'animal que pour le producteur, le consommateur, et l'environnement.

\section{Abstract}

\section{Digestive microflora of bird : factors of variation and consequences on bird}

The microflora of the digestive tract, remained uncompletely known due to the conventional methods used so far. It is mainly located in the crop and the caeca, but also, although in lower number, in the small intestine. In the upper part of the digestive tract, facultative anaerobes dominate, whereas in the caeca it is mainly obligate anaerobes that are present. The microflora depends on numerous factors such as individual, animal age, environment, and diet. Bacteria produce various metabolites that can be useful or detrimental to the host. Interactions between bacteria and the gastrointestinal epithelium lead to various structural and functional modifications of the digestive tract. Bacteria can decrease lipid digestion and may modify carbohydrate and protein digestion. They cause an increase in energy and amino acids requirements. They have a negative impact on vitamin nutrition. Beneficial bacteria can protect against pathogens through a competitive exclusion process. Moreover, the flora is implied in the development of the intestinal immune system. Globally bacteria have a negative impact on bird growth. They may also have an effect on the quality of meat and eggs. Improved knowledges of the microflora of the digestive tract and of its consequences should contribute to its control and to use it beneficially for birds as well as for breeders, consumer and environment.

GABRIEL I., MALLET S., SIBILLE P., 2005. La microflore digestive des volailles : facteurs de variation et conséquences pour l'animal. INRA Prod. Anim., 18, 309-322. 